This item was submitted to Loughborough's Research Repository by the author.

Items in Figshare are protected by copyright, with all rights reserved, unless otherwise indicated.

\title{
Voice: Sonic geographies of childhood
}

PLEASE CITE THE PUBLISHED VERSION

http://dx.doi.org/10.1080/14733285.2017.1287879

\section{PUBLISHER}

CTaylor \& Francis (Routledge)

\section{VERSION}

AM (Accepted Manuscript)

\section{PUBLISHER STATEMENT}

This work is made available according to the conditions of the Creative Commons Attribution-NonCommercialNoDerivatives 4.0 International (CC BY-NC-ND 4.0) licence. Full details of this licence are available at: https://creativecommons.org/licenses/by-nc-nd/4.0/

\section{LICENCE}

CC BY-NC-ND 4.0

\section{REPOSITORY RECORD}

Mills, Sarah. 2019. “Voice: Sonic Geographies of Childhood”. figshare. https://hdl.handle.net/2134/23475. 


\title{
Voice: Sonic Geographies of Childhood
}

\author{
Sarah Mills, Department of Geography, Loughborough University
}

To cite: Mills, S. (2017) Voice: Sonic Geographies of Childhood, Children's Geographies http://www.tandfonline.com/doi/full/10.1080/14733285.2017.1287879

This article uses the sonic geographies of childhood as an entry point into long-standing and important debates in the sub-discipline on 'voice'. The article uniquely explores children's voices from the past through considering a different type of research material - archival audio recordings. It argues that literally listening to past children's voices (and noises, sounds and silences) can offer fresh insights into the concept of voice that tends to be associated with contemporary contexts. Drawing on archival encounters with 'second hand' field recordings of children across different schools and playgrounds in London in the 1960s, this article engages and extends wider theoretical debates about childhood, voice and memory. The article calls for more attention to the unique characteristics of sound and wider soundscapes of childhood. The article critically reflects on the possibilities and tensions associated with such work.

\section{Introduction}

What does childhood sound like? How do we engage with children's sounds and voices from the past? Why does this matter for children’s geographers? This article interrogates these provocative questions and contributes to work in children's geographies through exploring the sonic geographies of childhood and voices from the past. Specifically, it considers these questions through the example of sounds, noises and silences made by a number of children from 1960s London. These were recorded in a primary school teacher's pedagogical research project in schools and playgrounds, with material currently held in an archive of children's folklore. This article uses archival encounters with this 'second hand' research material as an entry point into some wider theoretical debates about childhood, voice and memory in the context of past childhoods. 
Clearly, not all childhoods 'sound' the same and neither do children's voices. Childhood is widely recognised as a social construction and children's lived experiences are not universal, but rather are shaped by political, economic, social and cultural dynamics over time and space (Jenks 1996; James, Jenks and Prout 1998, Holloway and Valentine 2000; Ryan 2012; Holloway 2014). A wealth of literature from children's geographies and the new social studies of childhood has sought to unpack these characteristics and differences, and has done so through an overwhelming focus on children's voice (as discussed by Kraftl 2013; see also Holt 2004 and Philo 2011). Indeed, a key conviction of work on geographies of children, youth and families as an intellectual project with diverse threads and histories (Holloway 2014) has been to challenge the refrain that "children should be seen and not heard" (Valentine 1999) and to champion methodological approaches that prioritise children's voices to redress power imbalances. As researchers that (largely) seek to elicit or create space for the views and experiences of children and young people to emerge through oral speech and conversation, one could therefore describe the majority of work in the sub-discipline as being facilitated by, or involving, sound. Indeed, it is hard to imagine most research projects in this field - even those that involve creative visual methods - without the recorded sound files of interviews, or without 'voices’ (of both the researcher(s) and the researched).

For other geographers however, sound and noise have been more than a necessary social interaction to the fieldwork process, or more than a philosophical approach and conviction to listen to children's voices, but have instead been the focus of their studies. Michael Gallagher's insightful work on school, power and discipline (2010, 2011) did not deploy a methodology merely attuned to the sounds of school life or attempt to simply capture those, but instead considered sound, noise and hearing more broadly (leading to wider disciplinary contributions on phonics and audio geographies, see Gallagher and Prior 2014; Gallagher 2015). Other recent work in the sub-discipline has considered young people’s engagement 
Accepted for publication $16^{\text {th }}$ November 2016, Published Online $12^{\text {th }}$ February

with radio and music projects as both a platform for youth voice (Dickens and Lonie 2013; Wilkinson 2015a, 2015b) and as a vehicle for participatory political engagement (Benwell et al. 2013). Running parallel to these empirical foci on sound, music and radio have been further theoretical contributions on childhood, voice and memory that are discussed more fully in the next section.

In this article, I seek to invigorate and extend the above debates through some new entry points and the consideration of a different type of research material - audio recordings from the past. I explore how these past sounds of children's voices and spaces of childhood might challenge some dominant ideas within the sub-discipline. I argue that historical data can offer a fresh insight into the concept of voice that immediately tends to be associated with contemporary children and childhood(s). Closer attention to the sonorous may also open up spaces of childhood that have thus far been difficult to access for adult researchers. This article is therefore an attempt to engage imaginatively and creatively with past research material that has theoretical threads and implications (Horton and Kraftl 2005) as part of growing (yet relatively limited) work on the historical geographies of childhood and youth (e.g. Ploszajska 1996; Gagen 2000; Nicholson 2001; Karsten 2005; Cameron 2006; De Leeuw 2009; Philo 2016). Furthermore, this article also chimes with ongoing debates beyond children’s geographies: first, on soundscapes and audio cultures in cultural and historical geography (e.g. Anderson et al. 2005; Lorimer 2007; Peters 2011; Revill 2016); and second, research by historians on childhood, memory and archives (Stearns 2008; Tesar 2015; Gleason 2016) as well as sensory histories of education (Burke and Grosvenor 2011; Goodman, 2016). 
Accepted for publication $16^{\text {th }}$ November 2016, Published Online $12^{\text {th }}$ February

The next section of this article outlines relevant debates in the literature introduced above, followed by a methodology section. This article's central argument on the sonic geographies of childhood and children's voice is then structured in two analytical sections. These draw on empirical accounts of children's lives in 1960s London to embark on a wider contribution as outlined above. The article concludes with a summary of its contributions, as well as reflections on future debates and ethical questions.

\section{Exploring voice and memory: geographies of childhood, sound and space}

A cornerstone (if not 'mantra', see Kraftl 2013) of children’s geographies has been that children and young people are the experts of their own lives and therefore a focus on their voice is fundamental to research practice in the sub-discipline (and more broadly, see James 2007, Holloway 2014; Wilkinson 2015b). Indeed, contemporary discourses of participation and rights are cemented in children and young people's lives at multiple scales and revolve around the notion of 'voice'. Holt (2004) explains how listening to young people's voices acknowledges their rights and agency, yet cautions that all knowledge is partial and that the practices of 'empowering' research are complex. Philo (2011) has described the 'taboos' and uncomfortable relationship the sub-discipline may have surrounding when not to listen to children, and Kraftl (2013) has made an impassioned call for moving 'beyond' voice in a recent article on children’s emotional geographies. These articles are not suggesting a move away from child-centric research that has provided rich and stimulating work in children's geographies, but rather each has provided a critical engagement with theory and praxis for the sub-discipline’s future (see also Vanderbeck 2008; Holloway 2014).

Here, I want to engage and extend some of these ideas about listening to children and young people’s voices by considering those from the past. I do not mean an engagement with 
Accepted for publication $16^{\text {th }}$ November 2016, Published Online $12^{\text {th }}$ February

contemporary adult voices through oral histories that excavate memories about childhood (Riley and Harvey 2007), or carving out space for children’s voices and agency in written historical material (Gagen 2001; Mills 2012; Gleason 2016). Rather, I am describing an equally valid (yet fraught) engagement with the actual recorded voices (and sounds, noises and silences) of children from the past captured on file. Access to this type of research material may seem rare, but it is certainly not a complete absence from the historical record or archival landscape; audio material is increasingly available to the researcher in formal and personal archives. To be able to listen to children's voices from the past provides a material and methodological opportunity - however rare or partial - to engage with past childhoods. Indeed as Kraftl (2016) notes, there are inherent tensions in accessing past childhoods and sub-disciplinary dilemmas that have yet to be resolved. One contribution here in this article then, is to challenge how most reflections on voice in the sub-discipline relate to first-hand contemporary fieldwork with children and young people. What can be garnered from the use of audio material that unlocks past (children's) voices - literally - through audio archives? I argue this type of project can provide unique opportunities for exploring past childhoods, despite the dilemmas of using second-hand material that this article grapples with. This article is also concerned with a specific type of voice, that of pupil or student voice, as the audio recordings are of primary schoolchildren (see Bragg 2007; Robinson \& Taylor 2007). This distinction is important for context, but also at a conceptual level, discussed later in relation to the history of education (and educational research) as a historical and methodological counterpoint to Cremin et al.’s (2011) visual methods work on problematising pupil voice.

Inevitably, a project of this kind sparks questions about the ability of an adult researcher to 're-enter' childhood and its 'otherness', to accurately listen to and represent children's lives. These questions have long concerned children’s geographers (Aitken 1994; Philo 2003; Jones 
2001, 2003), but are important to highlight in the context of this article, especially because of methodological debates on memory, auto-ethnography and our own (past) childhoods (see Horton and Kraftl 2006, 2012; Kraftl 2016). In engaging with original recorded source material from the 1960s, I do not assume that adult researchers today can unproblematically understand and represent past children's voices any 'easier' than it is to understand or traverse children's worlds in the present. Yet, I call for more sustained attention to the sonic, sonorous and aural expressions that might push us closer, whilst recognising the futility of trying to capture the entirety of childhoods (see Philo 2003) - whether these are contemporary or historical. It is also worth highlighting here that debates on memory in the sub-discipline are connected to literature on children’s imaginative geographies and (un)truths (e.g. Philo 2003; von Benzon 2015). Engagements with creative child-centric historical material therefore complicates popular understandings of archival data and archives themselves as housing objective ‘truths' (Mills 2013). I argue that just as it is impossible for those working in contemporary contexts to ascertain the 'absolute truth' in interviews with children and young people (or importantly any human participant regardless of age), accounts in historical material by 'young ghosts' are also partial (Mills 2012).

In calling for more attention to the sonorous and aural dynamics of children's voice recordings, I want to outline recent literature debates in cultural geography on sonic geographies. A focus on the senses as a way of knowing and representing the world has been a long standing area of human geography, with important work on sound in relation to the cultural politics of music (Smith 1997) for example. However, a number of cultural geographers have recently discussed the 'geography of voice' that focuses on the politics of listening / speaking (Gallagher, Kanngieser and Prior 2016; Kanngieser 2012; Bennett et al. 2015) as well as exploring music in different contexts (e.g. Anderson et al. 2005), sound 
Accepted for publication $16^{\text {th }}$ November 2016, Published Online $12^{\text {th }}$ February

archives (Lorimer 2007), radio cultures (Peters 2011), sonic geographies (Matless 2005), the spatial distinctiveness of sound (Revill 2016) and its emotional and affective geographies (Doughty, Duffy and Harada, 2016). In this article, I consider the difference audio material makes to ideas about children's voice and the qualities and characteristics of (past) sound that, as hinted earlier, shape representations of childhood and the re-telling (or re-hearing) of children’s experiences. To define or describe sonic geographies is complex;as Revill (2016) notes, sound is both medium, method and modality. I argue that there is a real need to examine these dynamics in children's geographies research where a focus on voice has been so central to scholarship. Finally, there are wider sonic geographies of childhood played out in society and space that are discussed throughout this article.

\section{7-013/AC (Audio Cassettes): Methodology and sonic archival encounters}

This article draws on fieldwork at the Nigel Kelsey Collection of Children's Folklore held at the Special Collections Department, University of Sheffield Library. This is a small collection that holds 44 sound recordings (39 cassette tapes and 5 open reel items) alongside written material, in contrast to some larger formal sound archives. The material is the result of Nigel Kelsey’s pedagogical research (1966-67; 1982-84) and a lifetime’s interest in children’s folklore. Kelsey (1919-1990) was a primary school teacher and later headmaster in London who began to informally record playground 'language' and then embarked on a Diploma in Education at the University of London (awarded 1969) with a thesis on children's speech (Wiltshire 2001). His fieldwork across a number of schools in London was followed by an extensive but unfortunately unfinished monograph project in the 1980s on children’s folklore (although see Kelsey 1981 for a published article). Both periods of fieldwork were dominated by sound, with material later bequeathed to the University of Sheffield's Archives of Cultural Tradition (University of Sheffield 1999; Wiltshire 2001; Widdowson 2014). 
In my engagements with these original sources, and specifically on those from the 1960s, I was not focused on regional children's folklore per se, but rather on the childhoods enfolded into this sound-making project. Kelsey was trying to preserve original playground sounds and 'the oral traditions circulating, dying out and being produced, by children aged about ten' (Kelsey, cited in Wiltshire, 2001: 84). We can read this as an attempt to capture the ‘collective’ or 'separate’ culture of childhood in playground games and songs that James et al. describe (1998: 99; see also Opie and Opie 1959; on playgrounds more broadly see Gagen 2000; Harker 2005; Bergin Wilson 2014). There is a sense throughout the whole archival collection that Kelsey was collecting, recording, and seeking to rescue this (childhood) folklore (on such practices, see MacDonald 2011). In addition to these playground sounds, Kelsey’s tapes also recorded original indoor focus-group style data collection. The competing playground noises must have influenced his decision to conduct small focus groups inside schools as a less organic but clearer way of capturing individual 'snippets' of folklore. Here, Kelsey recorded speech, language, rhymes, songs, jokes and riddles, as well as prompting free conversation and some use of set questions with children from both working-class and middle-class families. This fascinating secondary data source therefore gives an insight into these children's everyday lives in 1960s London, frozen in time. In that sense, it is important to locate these recordings within the wider post-war architectures of childhood in Britain (Kozlovsky 2013) and broader social, political and economic change during the 1960s (Marwick 1990; Rycroft 2011). However, I argue that audio archives involve much more than simply storing and capturing time (or childhoods) through technical media (Kittler 1999), but rather enable a re-performance of traces from the past (see Gallagher 2015; Gallagher and Prior 2014). This type of archival work with audio materials involves the reenactment - often repeatedly - of events and conversations, as well as songs and riddles in this project on the sonic geographies of childhood. 
The archival fieldwork for this project involved listening to each tape at least three times: first, without any note-taking or pauses to hear them as complete recordings; second, a more intense process of listening in shorter bursts, making my own analytical notes; finally, a third playback alongside Kelsey’s written transcription and notebooks. A number of significant recordings, such as those drawn on in this article, were listened to multiple times, often played back with small changes to the speed or volume of the recording to better engage with the properties and qualities of sound and the children's voices.

Cultural and historical geographers have increasingly reflected on the emotional encounters and experiences of archival research (Bailey et al. 2009; Mills 2013). In this project, I did not visit the schools based in London, rather acknowledging Kelsey’s original scholarship. Yet I was transported to these educational sites, if only partially, through listening to the cassette tapes during archival fieldwork. A surprising connection between the sounds of strangers' childhoods in the 1960s and my own more recent childhood emerged. Indeed, sound had a unique capacity to elicit and evoke memories and connections between Kelsey’s field sites and the spaces of my own childhood. For example, many of the playground songs Kelsey recorded in 1966-67 were remarkably similar to those from my primary school experiences in the West Midlands between 1990-96. On one hand, these nostalgic connections were comforting and humorous; on the other hand, it was troubling to hear racist and sexist songs that had reverberated around my own primary school playground too. For example, hearing "We are the can-can girls (of 1962)" on tape and then instantly singing out loud "We are the Milner girls” based on memories from my school 'Milner' with similar lines about smoking, drinking and other 'grown up' activities, much to the amusement of other researchers in the room and my embarrassment.

The lyrics of playground songs reveal moral geographies of childhood in expressive, sometimes crude, ways - challenging popular constructions of childhood and the playground 
as innocent. Through sound-work in the archive, there was an opportunity to listen, hear and reflect critically on past childhoods (of others and my own) and to discuss these ideas with family and friends. There was, to some extent, a co-production of knowledge in how I shared (or sang) archival traces back to my parents, who were at primary school during this time period, albeit in a different city and context. I recalled (uncensored) rhymes and tonguetwisters with my brother and cousins. This further emphasises my earlier argument that audio archives enable a re-performance of traces from the past, not just the capacity to store them. I also had some difficult but important discussions with friends about the racist and sexist songs mentioned above, once familiar echoes and performances in our own sonic geographies of childhood. It would be impossible to research and write about such a collection of audio material without at least acknowledging these personal (re)imaginations of one's own childhood, positionality, and the input of family and friends that are often marginalised in discussions around the co-production of knowledge.

My focus now turns explicitly to Kelsey’s recordings and children's voices to demonstrate this article's broader argumentation and contribution. Due to the relatively recent time period under discussion, pseudonyms have been used for the children quoted in this article (Mills 2012) and audio material is not presented in a digital format due to copyright permissions. Rather, I use written transcripts augmented with descriptions of sound. This inevitably creates another layer of representation, discussed shortly, but is an important methodological consideration and challenge. As such, I have tried to bring the reader as close as possible to the recordings through noting pauses, background noise, pronunciation and obvious tonal changes in accent (see Turner 2016 on these dilemmas). 
Accepted for publication $16^{\text {th }}$ November 2016, Published Online $12^{\text {th }}$ February

\section{The representational politics of listening to (past) children's voices}

Kelsey's tapes recorded a wealth of content, but primarily past children's voice(s) and the wider soundscape of school, for example:

[Tape crackles and a microphone is grabbed]...

Nigel Kelsey [NK]: Then you pass it on to the next person...you start...

Craig: Each peach pear plum, choose your best chum

[4 seconds of silence - a bell rings in the distance]

NK: Pass it on, and go round clockwise

[Children giggling]

Pauline: Ham bacon pork chop, ahh you must stop

Robert: Ibble bobble black bobble ibble obble out

Sally: Eenie meenie macaraca naar niii dominaca nika naka lollipoppa omm pomm push out ip dip boy scout walk OUT

[More giggling and muffled repetition of Sally's song]

NK: Go round that direction!

[Group bursts into the song 'Who's gonna marry spotty face']. ${ }^{1}$

In this written transcribed extract, it is clear that didactic adult-child relations shaped this (sonic) fieldwork encounter. Yet these dynamics are clearer still when heard on tape.

Kelsey’s firm instructions evoke his power as an adult, a researcher, and as a primary school teacher. However, he is not the teacher of the group of children quoted here from another primary school in Walworth, South London. In that sense, he embodied someone that sat between a responsible adult, observer and friend, or as Holt (2004) describes the 'least-adult'. The recorded interview format would have been a unique opportunity for these 10 year old children to participate in such a project, yet perhaps not as unusual as one might assume. 
Tracey Skelton (2008) offers a personal reflection of when a teacher (Mr Manchester) asked her to participate in a recorded short interview for his teacher training project, also aged 10. She reflects on the impact of that experience on her life and career, discussing this in relation to debates on participation and research practice. Although I cannot ascertain the impact that Kelsey’s projects had with (now adult) participants, I return to a discussion about the opportunity to participate in such a project and have your voice 'heard' in the next section.

As hinted, we lose something in the written extract above compared to hearing the sound clip. The politics of representation has long been discussed within geography and across the social sciences, but in the context of this type of material, we also miss the pace, timbre, pitch and performative speed of the rhymes through the process of transcription that bursts from the sound clip. The children’s initial hesitation and silence moves on to an impromptu sonic 'take-over’ in this extract. This chimes with some of Kanngieser’s (2012) exploration of the different characteristics of sound, that silence can be a "refusal to participate" but also "mark[s] the impossibility of translation and the limitations of language, masking confusion, fear, introversion...” (2012: 344). For the children recorded here to share their 'own' culture - orally and aurally in Kelsey’s project - it needed his prompts and perhaps the realisation that other children were sharing and singing in this space too, ultimately ending with the children’s multiple collective performance.

In addition to the voices of schoolchildren, Kelsey’s tapes also captured (and now re-perform) the past sounds of school life: a bell, a scraping chair, a football match, a fight, and so on. In part, this echoes Michael Gallagher's opening account in his contemporary study of how early morning playground noise at a local primary school built "steadily into a raucous cacophony, a swirling mass of laughter, shouts, chirps and screams reverberating around the playground” (2011: 47). A similar cacophony posed a challenge for Kelsey in his recordings across school spaces - in the playground, classrooms and corridors. Each of these spaces 
hosts a slightly different 'architecture' of sound: both in terms of acoustics and privacy. I was keen to hear this wider soundscape on the original recordings - the way in which space and sound are co-created (Kannfieser 2012; Revill 2016) - rather than the transcribed notes prepared in the archive. I was scared about too much distance and missing context, phrasings, utterances, background noise and all the other more-than-representational-'ness' that I presumed would be on the tapes. Take, for example, this brief sound bite from 1967 of free conversation between two schoolchildren from Marylebone, London:

Janet: Hilary hasn't got a fear of anything because everything's feared...scared of 'er. She's like a cannon. She'd crush a rhino.

Gill: I like tadpoles and newts and my very big fear is Hilary. ${ }^{2}$

When reading these lines on paper, this is a humorous or at least mildly amusing exchange between two children. However, when heard as a sound clip through headphones, the clear emotional fear in Gill's voice as a whisper and broken stutter is anything but humorous (on emotional dimensions of sound, see Duffy and Waitt, 2013). Sound matters then in providing context and layers of meaning, as qualitative researchers in the social sciences have long highlighted in relation to the dynamics of interviews beyond the transcribed text; the difference here is that I was never in the room in the first place. I argue that sound, and archival audio material especially, has the power to transcend space and time. There are however multiple 'distances' and processes of translation at play here: the live sounds of the original fieldwork exchange - the recording by Kelsey onto reel-to-reel tape - the cassette tape copies made by an archivist for preservation purposes - the listening process through my headphones - the written extracts used in this article. This is not just an issue for a project about childhood, but speaks to wider debates on representational politics and historical research (Gagen 2001; Lorimer 2009). Audio archives have the potential however to bring us 
more proximate (Revill 2016) to (past) children's voices through the capacities of sound - to hear Gill's fear about cannon-like Hilary as a whispered-stutter, rather than simply read the statement. Here, intimacy works through the sonic qualities of the recordings themselves, creating a moment where the listener becomes enfolded in the past (see Peters forthcoming).

The above extract from Janet and Gill also importantly demonstrates the dangers in romanticising sound, and indeed childhood. There were times that my archival experiences were dominated by powerful silence and uncomfortable sounds, smashing conceptions of childhood in the past as wonderful and care-free. These included listening to children's fears and some isolated accounts of upsetting times in their lives. For example, these three separate extracts from Sharon on three different days of recording at a school in Brockley, South London:

Christmas before last my mum and my dad ........I just come in and my mum and dad was having a row. And all of a sudden I went upstairs in my bedroom so I would be out of the way in case a fight or anything started and when I was up there I heard a crash. I come down and it was my dad. He had picked up the Christmas tree and threw it. ${ }^{3}$

My mum has something wrong with her lungs and she won't tell us what it is. ${ }^{4}$

I wish my...brother Jeremy was still alive. ${ }^{5}$

In contrast to Katy Bennett et al.’s approach of developing “good research practices for listening to complex stories of hardship, loss, disorientation and exclusion” through "repeated and sustained connection with people and places” (2015: 8), in these instances in the archive room I felt useless and struggled with the ethics of a (dis)embodied research encounter involving a (past) child such as Sharon. I use (dis)embodied because that child was 'present' in the room through their own recorded voice and the materiality of the tape recording - but 
Accepted for publication $16^{\text {th }}$ November 2016, Published Online $12^{\text {th }}$ February

Sharon was a 'young ghost' (Mills 2012). The listening I was engaged with though - whilst detached from a research participant in the flesh - was still an "active, sensuous and embodied approach to listening” (Bennett et al. 2015: 9) that involved “ears, eyes, beating hearts, feelings, skin, pores, tingly, hair raising moments and more besides” (2015: 9). The above extract raises ethical questions about the types of conversations that unfolded in Kelsey’s fieldwork, of Sharon's 'place’ in the archive as someone probably still alive, and about my ability or failure to hear and listen to the different voices and contexts (Pratt 2010). Overall, these extracts from Sharon chime with a whole series of academic debates on the realities of children's everyday lives as social and political beings not just becomings (see Holloway and Valentine 2000; Uprichard 2008). They also demonstrate how space was created in Kelsey's project for children's own voices, ideas I develop further in the next section of this article.

\section{Sounding 'childish' and 'grown up': having your voice 'heard’?}

Children’s voices were central to Kelsey’s sound-making project and fieldwork. During the conversations that interject between playground songs, the children talk about frustrations with parents, school and siblings as well as the strange, banal and imaginative. The tapes recorded everyday experiences, memories and stories, as well as fears and hopes for their present and future selves. In this sense, most of the research material resonated with, or had echoes of, contemporary fieldwork on the geographies of children, youth and families. There was a familiarity in the material that streamed into my headphones. Indeed, apart from the direct references to Cilla Black, the Beatles and hipster skirts, most accounts could have easily sounded like they were from 2016 (including, depressingly, accounts of poverty). However, one must be careful here not to dilute the experiences of these children from 1960s 
London and reduce these accounts to similarities with contemporary childhoods, or vice versa. There are real dangers here in merging what mattered to children then with what matters to children now (Horton and Kraftl 2006), further deepening an adult-imposed universalising of childhood through collapsing time as an important variable in the geographies of children and young people’s lives. Nevertheless, there are perhaps similarities in childhood experiences that should be highlighted: why is it that so much of the content on these tapes felt familiar? This line of thinking runs contrary to much scholarship that emphasises change over time, or the individual unique characteristics of children's everyday lives. But what does it mean if so much of the content was repetitive and 'universal', when as researchers we should not ‘universalise’ childhood?

Although Kelsey used some prompts to spark discussion, most of the topics from his fieldwork came up in free conversation with a natural flow and could be described as 'childish'. These unsurprisingly included discussions of friendships, hobbies and most of all school. Tales of school dinners and teachers litter the material, for example:

This is [our] School. I like my teacher and Mr Bond takes us up the Rec [Recreation Ground] every Thursday and Friday he takes us swimming and Alec Turner loves Karen Buxton. ${ }^{6}$

I used to run over the playground in me pants [laughs] and I used to go - I used to go over this old lady's 'ouse and eat her rotten sausages.

We can pose questions here about the murky grey area of “'untruth’, 'lies’, ‘imagination’, ‘fantasy’, ‘obfuscation', ‘exaggeration’ and ‘fiction’” (von Benzon 2015: 332) and childhood 'reverie’ (Philo 2003) recorded on Kelsey’s tapes. In some cases, the repeated acoustics of ‘one-up-man-ship’ in children’s stories and tonal intonations help to identify some of these boundaries: one can hear when the ripples of giggles begin to surface and when children were 
exaggerating to have fun with this adult visitor. 'Childish' tales of school life and being naughty echo themes across a number of recorded songs, for example:

\author{
Come to our school, \\ Come to our school, \\ It's a place of misery. \\ Round the corner there's a signpost, \\ Saying "Welcome unto thee" \\ Don't believe it \\ Don't believe it \\ It is just a pack of lies \\ If it wasn't for the teachers \\ We'd be home in paradise. ${ }^{8}$
}

Beyond this type of material, I argue that Kelsey’s research also created a space for children to engage in 'grown-up' conversations. This pedagogical research project from the 1960s can therefore be seen as an early example of 'giving' children a voice. Whilst remarkably similar to some fieldwork projects in geography today, clearly different researchers have different impulses, epistemologies and subject-positions (Vanderbeck 2008) and I am conscious of the distance here in making claims about Kelsey’s aims and philosophical approach. I now present two examples of children expressing ideas in (past) research settings to further illustrate my argument: first their opinions on school, and second on post-war leisure cultures.

On some tapes, children talk about changes they would like to see at their school. This impulse resonates with contemporary discourses of participation and democratic citizenship in children lives, for example the prevalence of school and youth councils in the UK that are designed to give them a voice (Matthews 2001; Wyse 2001) - 'productive' sound and noise on panels or committees. This is in marked contrast to the early history of schooling in the nineteenth century when noise was regulated and punished. Kelsey's research may therefore represent a particular moment in the history of education (and educational research) in 
relation to pupils' voices being sought out and noise (partly) encouraged. ${ }^{9}$ Take this extract of free conversation at a mixed-school in Brockley:

Geoff: When we go out to play we only have fifteen minutes and I would like (er) thirty minutes for play.

Debbie: One day if Mr Brennan asked us into his office to ask us if we would like anything changed in the school, I would say "I don't like to have Geography and History".

Julie: I would like to go in the boys' playground instead of the girls' playground at dinner time.

Mark: I would like to have the playgrounds mixed and more bigger and the library and the classes bigger.

Sophie: I haven’t got anything to say. ${ }^{10}$

This extract illustrates how these children created a type of informal 'forum' with Kelsey, yet his silence on tape about these issues perhaps reflects his lack of power to do anything about these suggestions in the educational landscape of that time. We can ask whether these children were really heard or listened to in the way we might envision for research with children and young people today. Furthermore, Sophie’s remark that “I haven’t got anything to say” is striking. We see how voice is used to express an absence of opinion, or that Sophie did not know how to respond, had forgotten her line of thought, or perhaps had hearing difficulties (see Kraftl 2013; von Benzon 2015; on D/deaf young people’s geographies, see Skelton and Valentine 2003). On other tapes children mishear Kelsey or other children, play on words, misinterpret statements as questions and vice versa.

To extend this discussion on the expression of children's opinions through voice in research settings, the next example on post-war youth culture also illustrates ideas about 'sounding adult' or 'grown-up'. In a school in Palmer’s Green, North London, children are recorded 
passing negative judgement on post-war cultures of leisure, adopting a tone that one would usually associate with adults:

John: I think these mods and rockers ${ }^{11}$ look absolute asses in these er leather jacket things with stars and stupid things like 'I'm a mod' on and they go tearing about on motor bikes and a perfect menace to the community really. ${ }^{12}$

This 'adult'-sounding description of mods as a 'perfect menace to the community' from a 10 year old child is a unique perspective, emphasised by the child's serious tone on tape. I suggest John's critique was in part due to the 'adult' like setting Kelsey had created, where children were sharing their views and engaging in the 'art of conversation'. The discussion continues with other anecdotes:

Kate: My brother... whenever he sees a mini-skirt he goes raving mad really and er I don't think mini-skirts are very attractive. On these girls who've got fat legs they look really sickly...I saw a girl the other day with a plastic mac on well it - which was quite short and it...Mum and I couldn't stop ourselves from laughing you know it really put me off my dinner...I hope I don’t grow up to look like that.

This 'grown up' approach to cultures of leisure in 1960s London reflects some wider politics and experiences of childhood: these 10 year old participants wanted to avoid growing up like these teenagers, yet in a few short years, these leisure practices would be familiar to them and perhaps embraced. The culture of the 'teenager' was also filtering down to the primary school playground, with the following song on another tape:

Hey there darling, how about a date

Let's go down the coffee bar, I know one that ain't too far

Say there darling, won't you come along Just do what I tell you and you can't go wrong. ${ }^{14}$ 
More broadly though, these extracts from John and Kate echo Kraftl’s (2013) observation that “some participatory processes manufacture children’s emotions into a more-or-less acceptable form of voice”, transforming feelings into 'reasoned' argumentation (2013: 15). The length of Kelsey's tapes suggests these children enjoyed the opportunity to be part of his educational research - most of the material sounds fun. Nevertheless, we should recognise that the same participatory process that afforded these children a voice, could, in other cases, have created emotional distress or anxiety (see de Leeuw 2009; Kraftl 2013), as my previous reference to uncomfortable sounds of silence and upsetting stories demonstrated. Therefore, we can consider the processes by which children are 'given' voice, or were 'given' voice in the past. It is again worth highlighting the dangers of romanticising the research material used in this article (and by extension childhood in 1960s London) when these recorded fragments are partial. I am keen to stress that the accounts here are the experiences of these children, in these primary schools in London, between 1966-7, captured on tapes that contain what these children chose to reveal or not. This still though, for me, is 'authentic' and 'valid' research material to use in the study of children's geographies. However, it is vital to consider a recent question posed by historian Mona Gleason about "those children... whose voices we cannot hear no matter how hard we listen - do their histories 'count' in the same way?” (2016: 457). I end now with a summary of this article's contributions and reflections on the wider sonic geographies of childhood and ethical dilemmas associated with accessing past children's voices.

\section{Conclusions}

This article has contributed to ongoing sub-disciplinary debates about the relationship between childhood, voice and memory through a unique discussion of past childhoods that considered a different type of historical data - audio material of past children’s voices. At a 
basic level, it is a different way in which children can 'speak' in our research. I hope this article has also challenged the notion that contemporary children's voices are heard (and listened to) whereas those from the past are impossible to hear and are 'trapped' in written material or must be accessed via oral histories with adults. The children in Kelsey's fieldwork have been heard by multiple audiences (Kelsey, archivists, researchers) in a relatively unique setting. However, this article has alluded to how the voices of children in both historical and contemporary contexts are partial, fragmented, and wrapped up in the politics of representation. This article sought to complicate ideas surrounding the process of giving voice, the extent to which (past) children are able to speak in research, and how audio archives and the capacities of sound might bring us closer to those voices, without fetishizing or romanticising them. Debates on voice and memory are worthy of more sustained in-depth theorisation and critical debate, and I believe the sonic geographies of childhood - captured in time, re-performed and played out in future time-spaces - can provide an entry-point for further conversations, not least as part of genuine inter-disciplinary debate with historians. I now provide two starting points for discussion.

First, what are the wider sonic geographies of childhood? This article has primarily focused on the sonic geographies of (past) children's voices, with reference to the soundscapes of the playground and school. There is a wider relationship between childhood, sound and space though, especially in the context of memory. Comay describes how we are living in “memory-obsessed times” (2002: 12, cited in Tesar 2015: 103) and I want to suggest further research on this in relation to the shifting geographies of child/adulthood. For example, the recent popularity of 'Buzzfeed' - a website that hosts nostalgic 'list' articles including “33 sounds '90s kids will never forget” and "Can you identify these Pokémon by the sounds they make?”. Whilst clearly these articles are shaped by classed ideas of childhood in the Global 
North and popular culture (Horton 2012), the website reflects recent ideas about nostalgic returns to childhood with the 'death of adulthood' in popular American culture (Scott 2014) and the elasticity of age through the advent of 'kidults' (Labash 2016). These shifts are wrapped up in often lamented changes in children and young people’s lives and generational change (Karsten 2005). Sound and noise are crucial to these memory-fuelled ideas, and warrant further attention in this context. Indeed, more historical 'sounds' of childhood and youth will become available to researchers with technological advances and the passage of time, although this will clearly be shaped by the precarious funding landscape for most libraries and archives. Nevertheless, as archives increasingly house sound and audio content, how do we as researchers engage with these 'whispers in the stacks' (Paton 1990)? As online childhood traces from the 1990s and 2000s are currently being harvested by contemporary historians, moral questions remain about whose childhoods are saved, stored, or silenced, and further questions arise on the ethics of intimacy, editing, voyeurism, respect and dignity in relation to sound that are ripe for further discussion.

Second, how do we grapple with ethical questions surrounding secondary (audio) data? In this article, I have drawn upon research material collected by someone else having sought permission from an archivist, based on conditions of use after Kelsey’s death. In this project, listening to his tapes provided me with a unique (if not awkward) opportunity to listen to someone else's research encounter with children. This distance - of the author not collecting the data - has inevitably shaped my analysis and interpretation. Yet I argue that audio material, and specifically its ability to re-perform or re-enact past traces and events, has enabled a closer, more proximate connection to both the original fieldwork encounter and the process of analysis than written sources alone. This contemporary 'eavesdropping' represents an unusual research scenario of engaging with material decades after its production, 
acknowledging its source, and analysing this in the context of a different academic discipline. This may become a more familiar process and practice however with the increased archiving of contemporary research material. The project Kelsey undertook for his Diploma would have been one of hundreds across the country. What is unique is that his material was bequeathed and deposited, given value as a piece of children's folklore and archived (MacDonald 2011). This raises some provocative (and perhaps unnerving) questions about what happens to research material. Where will your (and my) recordings - tapes, CDs, digital files - go? What will be deposited? Original sound files or cleaned written transcripts? Whose voices will be heard? Silenced? Erased? What, then, are the sounds of children's geographies and what will the wider historiography of doing children's geographies look (or sound) like?

\section{Acknowledgments}

My biggest acknowledgment is to the late Nigel Kelsey for his original scholarship that inspired the wider ideas in this article. Thanks to the University of Sheffield Library Special Collections Department and Jacky Hodgson for archival support. Thanks to Jonathan Duckett, Louise Holt and Kimberley Peters for their insightful comments on an earlier draft version. This paper was presented at a Social and Cultural Geography Research Group meeting at the Department of Geography, National University of Singapore (hosted by Tracey Skelton) and the Institute of Historical Research, London as part of their 'History of Education' research seminar series. Finally, thanks to the anonymous reviewers and John Horton for their comments and editorial support.

\section{Funding}

This work was supported by the Institute of Historical Research via a Scouloudi Historical Award.

\section{References}

Aitken, S. 1994. Putting Children in their Place Washington DC: Association of American Geographers. 
Anderson, B., Morton, F. and Revill, G. (2005) "Practices of music and sound.” Social \& Cultural Geography 6 (5): 639-644.

Bailey, A., Brace, C. and Harvey, D. C. (2009) "Three geographers in an archive: positions, predilections and passing comment on transient lives" Transactions of the Institute of British Geographers 34 (2): 254-269.

Bennett, K., Cochrane, A., Mohan, G. and Neal, S. (2015) “Listening” Emotion, Space and Society 17: 7-14.

Benwell, M., A. Davies, B. Evans and Volunteers from KCC Live. 2013. Young People and stories of the riots: Liverpool 1981 and 2011 Blog available at:

https://livunigeog.wordpress.com/2013/11/12/young-people-and-stories-of-the-riotsliverpool-1981-and-2011/ [Access Date $14^{\text {th }}$ April 2016]

Bergin-Wilson, R. 2014. Who Owns the Playground?:Space and Power at Lollard Adventure Playground (1954-1961) University of Leeds, Masters of Arts by Research Dissertation

Bragg, S. 2007. “'But I listen to children anyway!'- teacher perspectives on pupil voice.” Educational Action Research 15 (4): 505-518.

Burke, C. and Grosvenor, I. 2011. "The hearing school: an exploration of sound and listening in the modern school.” Paedagogica Historica 47 (3): 323-340.

Cameron, L. 2006. "Science, nature, and hatred: 'finding out' at the Malting House Garden School, 1924-29.”, Environment and Planning D: Society and Space 24 (6): 851-872.

Comay, R. 2002. Lost in the Archives Toronto: Alphabet City Media.

Cremin, H., Mason, C. and Busher, H. (2011) "Problematising pupil voice using visual methods: findings from a study of engaged and disaffected pupils in an urban secondary school.” British Educational Research Journal 37 (4): 585-603.

De Leeuw, S. 2009. 'If anything is to be done with the Indian, we must catch him very young': colonial constructions of Aboriginal children and the geographies of Indian residential schooling in British Columbia, Canada, Children's Geographies 7 (2): 123-140.

Dickens, L. and Lonie, D. 2013. "Rap, rhythm and recognition: Lyrical practices and the politics of voice on a community music project for young people experiencing challenging circumstances”, Emotion, Space and Society 9: 59-71.

Doughty, K., Duffy, M. and Harada, T. 2016. "Practices of emotional and affective geographies of sound.” Emotion, Space \& Society 20: 39-41.

Duffy, M. and Waitt, G. 2013. "Home sounds: experiential practices and performativities of hearing and listening.” Social \& Cultural Geography 14 (4): 466-481.Gagen, E. A. 2000. "An example to us all: child development and identity construction in early 20th-century playgrounds.” Environment and Planning A 32 (4): 599-616. 
Accepted for publication $16^{\text {th }}$ November 2016, Published Online $12^{\text {th }}$ February

Gagen, E. A. 2001. “Too good to be true: representing children's agency in the archives of playground reform”, Historical Geography 29: 53-64

Gallagher, M. 2010. “Are Schools Panoptic?” Surveillance \& Society 7 (3/4): 262-272.

Gallagher, M. 2011. “Sound, space and power in a primary school.” Social \& Cultural Geography 12 (1): 47-61.

Gallagher, M. 2015. "Field recording and the sounding of spaces.” Environment and Planning D: Society and Space 33 (3): 560-576.

Gallagher, M., Kanngieser, A. and Prior, J. 2016 online. "Listening geographies: landscape, affect and geotechnologies.” Progress in Human Geography doi:10.1177/0309132516652952

Gallagher, M. and Prior, J. 2014. "Sonic geographies: exploring phonographic methods.” Progress in Human Geography 38 (2): 267-284.

Gleason, M. 2016. “Avoiding the agency trap: caveats for historians of children, youth, and education.” History of Education 45 (4): 446-459.

Goodman, J. (2016) Experimenting with sound and silence: auditory geographies, acoustic selves and sonorous histories of schooling, conference article at ECER 2016, Dublin

Harker, C. 2005. "Playing and affective time-spaces.” Children's Geographies 3 (1): 47-62.

Holloway, S. L. 2014. “Changing children’s geographies.” Children’s Geographies 12 (4): 377-392.

Holloway, S. L. and G. Valentine, eds. 2000. Children’s Geographies: Playing, Living, Learning London: Routledge.

Holt, L. 2004. “The 'voices' of children: de-centering empowering research relations.” Children’s Geographies 2 (1): 13-27.

Horton, J. 2012. “‘Got my shoes, got my Pokémon’: Everyday geographies of children’s popular culture” Geoforum 43 (1): 4-13.

Horton, J. and Kraftl, P. 2005. "For more-than-usefulness: six overlapping points about children’s geographies” Children’s Geographies 3: 131-43.

Horton, J. and Kraftl, P. 2006. "Not just growing up, but going on: Materials, Spacings, Bodies, Situations.” Children’s Geographies 4 (3): 259-276.

Horton, J. and Kraftl, P. 2012. "Clearing out a cupboard: Memory, materiality and transitions” in O. Jones and J. Garde-Hansen (eds) Geography and Memory: Explorations in Identity, Place and Belonging (pp. 25-44). Basingstoke: Palgrave Macmillan.

James, A. (2007) “Giving Voice to Children’s Voices: Practices and Problems, Pitfalls and Potentials” American Anthropologist 109 (2): 261-72. 
James, A., Jenks, C. and Prout, A. (1998) Theorising Childhood. Oxford: Polity Press.

Jenks, C. 1996. Childhood London: Routledge.

Jones, O. 2001. “'Before the dark of reason': some ethical and epistemological considerations on the Otherness of children” Ethics, Place \& Environment 4 (2): 173-178.

Jones, O. 2003. “'Endlessly Revisited and Forever Gone’: On Memory, Reverie and Emotional Imagination in Doing Children's Geographies. An 'Addendum’ to “'To Go Back up the Side Hill”: Memories, Imaginations and Reveries of Childhood' by Chris Philo, Children’s Geographies 1 (1): 25-36.

Kanngieser, A. 2012. “A sonic geography of voice: towards an affective politics” Progress in Human Geography 36 (3): 336-353.

Karsten, L. 2005. "It All Used to be Better? Different Generations on Continuity and Change in Urban Children’s Daily Use of Space.” Children’s Geographies 3 (3): 275-290.

Kelsey, N. 1981. "When They were Young Girls: A Singing Game Through the Century.” Folklore 92 (1): 104-109.

Kittler, F. A. 1999. Gramophone, Film, Typewriter, trans. Geoffrey Winthorp-Young and Michael Wutz. Stanford, CA: Stanford University Press.

Kraftl, P. 2013. “Beyond voice, Beyond 'Agency', Beyond 'Politics'? Hybrid Childhoods and Some Critical Reflections on Children’s Emotional Geographies.” Emotion, Space and Society 9: 13-23.

Kraftl, P. 2016. “Memory and Autoethnographic Methodologies in Children's Geographies: Recalling Past and Present Childhoods" in Evans, R. and Holt, L. (2016) Methodological Approaches, Vol. 2 of Skelton, T. (ed.) Geographies of Children and Young People Singapore: Springer, 1-23.

Kozlovsky, R. 2013. The Architectures of Childhood: Children, Modern Architecture and Reconstruction in Postwar London London: Ashgate

Labash, M. 2016. “Growing Old Without Growing Up” Weekly Standard Available at: http://www.weeklystandard.com/growing-old-without-growing-up/article/2000379 [Access

Date 23/5/16]

Lorimer, H. 2007. Songs from before - shaping the conditions for appreciative listening. In: Practising the archive: reflections on method and practice in historical geography, edited by E. A. Gagen, H. Lorimer and A. Vasudevan, London: RGS-IBG, 40: 57-74.

Lorimer, H. 2009. Caught in the nick of time: archives and fieldwork. In: The SAGE handbook of qualitative research in human geography, DeLyser, D., Aitken, S., Crang, M. A., Herbert, S. and McDowell, L. London: SAGE, 248-273. 
MacDonald, F. 2011. "Doomsday fieldwork, or, how to rescue Gaelic culture? The salvage paradigm in geography, archaeology, and folklore, 1955 - 62." Environment and Planning D: Society \& Space 29 (2): 309-335.

Marwick, A. 1990. British Society since 1945 Harmondsworth: Penguin Books

Matless, D. 2005. “Sonic geography in a nature region”, Social \& Cultural Geography 6 (5): 745-766.

Matthews, H. 2001. “Citizenship, Youth Councils and Young People’s Participation”, Journal of Youth Studies 4 (3): 299-318.

Mills, S. 2012. "Young Ghosts: Ethical and Methodological Issues of Archival Research in Children’s Geographies”, Children’s Geographies 10 (3): 357-363.

Mills, S. 2013. "Cultural-Historical Geographies of the Archive: Fragments, Objects and Ghosts", Geography Compass 7 (10): 701-713.

Nicholson, H.N. 2001. "Seeing how it was? Childhood geographies and memories in home movies.” Area 33 (2): 128-140.

Opie, I. and Opie, P. 1959. The Lore and Language of Schoolchildren Oxford: Oxford University Press.

Paton, C. 1990. "Whispers in the stacks: the problem of sound recordings in archives." The American Archivist 53 (2): 274-280.

Peters, K. 2011. "Sinking the radio 'pirates': exploring British strategies of governance in the North Sea, 1964-1991.” Area 43 (3): 281-287.

Peters, K. forthcoming. Sound, Sea and Society: Rebel Radio Basingstoke: Palgrave Macmillan.

Philo, C. 2003. “'To Go Back up the Side Hill': Memories, Imaginations and Reveries of Childhood.” Children’s Geographies 1 (1): 7-23.

Philo, C. 2011. "Foucault, sexuality and when not to listen to children” Children's Geographies 9 (2): 123-127.

Philo, C. 2016. "'Looking into the countryside from where he had come: placing the 'idiot, the 'idiot school and different models of educating the uneducable." Cultural Geographies 23 (1): 139-157.

Ploszajska, T. 1996. "Constructing the subject: geographical models in English schools, 1870-1944.” Journal of Historical Geography 22 (4): 388-98.

Pratt, G. 2010. "Listening for spaces of ordinariness: Filipino-Canadian youths' transnational lives.” Children’s Geographies 8 (4): 343-352. 
Revill, G. 2016. "How is space made in sound? Spatial mediation, critical phenomenology and the political agency of sound" Progress in Human Geography 40 (2): 240-256.

Riley, M. and Harvey, D. 2007. “Talking geography: on oral history and the practice of geography. Social \& Cultural Geography 8 (3): 345-351.

Robinson, C., and Taylor, C. 2007. "Theorizing student voice: Values and perspectives.” Improving Schools 10 (1): 5-17.Ryan, K. W. 2012. "The New Wave of Childhood Studies: Breaking the Grip of the Bio-Social Dualism?” Childhood 19 (4): 439-452.

Rycroft, S. 2011. Swinging city: a cultural geography of London 1950-1974 Farnham: Ashgate

Scott, A. O. 2014. "The Death of Adulthood in American Culture” The New York Times Magazine. Available at: http://www.nytimes.com/2014/09/14/magazine/the-death-ofadulthood-in-american-culture.html? r=0 [Access Date 23/5/16]

Skelton, T. 2008. "Research with children and young people: exploring the tensions between ethics, competence and participation.” Children’s Geographies 6 (1): 21-36.

Skelton, T. and Valentine, G. 2003. "It feels like being Deaf is normal”: An exploration into the complexities of defining D/deafness and young D/deaf people's identities.” The Canadian Geographer 47 (4): 451-466.

Smith, S. 1997. "Beyond geography's visible worlds: a cultural politics of music.” Progress in Human Geography 21 (4): 502-529.

Stearns, P.N. 2008. "Challenges in the History of Childhood.” Journal of the History of Childhood and Youth 1 (1): 35-42.Tesar, M. 2015. "Ethics and truth in archival research" History of Education 44 (1): 101-114.

Turner, J. 2016 online. "Voicing Concerns: (Re)Considering Modes of Presentation”, GeoHumanities http://dx.doi.org/10.1080/2373566X.2016.1211485

Uprichard, E. 2008. “Children as 'Being and Becomings': Children, Childhood and Temporality”, Children \& Society 22 (4): 303-313.

University of Sheffield. 1999. Archive List and Index: The Nigel Kelsey Collection of Children’s Folklore, September 1999

Valentine, G. 1999. "Being Seen and Heard? The Ethical Complexities of Working with Children and Young People at Home and at School.” Ethics, Place and Environment 2 (2): 141-156.

Vanderbeck, R. M. 2008. "Reaching critical mass: Theory, politics and the culture of debate in children's geographies” Area 40 (3): 393-400.

von Benzon, N. 2015. “'I fell out of a tree and broke my neck”: acknowledging fantasy in children’s research contributions.” Children’s Geographies 13 (3): 330-342. 
Accepted for publication $16^{\text {th }}$ November 2016, Published Online $12^{\text {th }}$ February

Widdowson, J.D.A. 2014. "Stumbling into folklore more than 50 years ago.” International Journal of Play 3 (3): 343-348

Wilkinson, C. 2015a. “Young People, Community Radio and Urban Life.” Geography Compass 9 (3): 127-139.

Wilkinson, C. 2015b. Connecting communities through youth-led radio. $\mathrm{PhD}$ thesis, University of Liverpool, available at: http://repository.liv.ac.uk/2037460/

Wiltshire, R. 2001. “The Nigel Kelsey Collection of Children's Folklore, 1962-1990.” Folklore 112 (1): 82-87.

Wyse, D. 2001. "Felt tip pens and school councils: Children's participation rights in four English schools.” Children \& Society 15 (4): 209-218.

\footnotetext{
${ }^{1}$ Nigel Kelsey Sound Collection, Archives of Cultural Tradition, University of Sheffield (hereafter NKSC/AOCT/UoS). Tape reference: 97-013/AC0061, 1983/1984

${ }^{2}$ NKSC/AOCT/UoS/97-013/1/9/37 3 May 1967

${ }^{3}$ NKSC/AOCT/UoS/97-013/1/6/18, 7 December 1966

${ }^{4} \mathrm{NKSC} / \mathrm{AOCT} / \mathrm{UoS} / 97-013 / 1 / 6 / 5,30$ November 1966

${ }^{5}$ NKSC/AOCT/UoS/97-013/1/6/13, 2 December 1966

${ }^{6} \mathrm{NKSC} / \mathrm{AOCT} / \mathrm{UoS} / 1 / 6 / 430$ November 1966

${ }^{7}$ NKSC/AOCT/UoS/97-013/1/9/1, 25 January 1967.

${ }^{8}$ NKSC/AOCT/UoS/Appendix 3 97-013/1/12

${ }^{9}$ Thanks to Prof. Gary McCulloch for prompting this reflection

${ }^{10} \mathrm{NKSC} / \mathrm{AOCT} / \mathrm{UoS} / 1 / 6 / 122^{\text {nd }}$ December 1966

11 'Mods and rockers' were post-war 'sub-cultural' groups involving distinct music and leisure styles.

${ }^{12}$ NKSC/AOCT/UoS/97-013/1/10/21, 24 May 1967

${ }^{13} \mathrm{NKSC} / \mathrm{AOCT} / \mathrm{UoS} / 97-013 / 1 / 10 / 21,24$ May 1967

${ }^{14}$ NKSC/AOCT/UoS/97-013/1/15/7, January - February 1967
} 